\title{
Effect and Mechanism of Herbal Ingredients in Improving Diabetes Mellitus Complications
}

\author{
Esmaeel Ebrahimi, ${ }^{1}$ Saeed Shirali, ${ }^{2, *}$ and Reza Afrisham ${ }^{1}$ \\ ${ }^{1}$ Student Research Committee, Ahvaz Jundishapur University of Medical Sciences, Ahvaz, IR Iran \\ ${ }^{2}$ Department of Laboratory Sciences, Hyperlipidemia Research Center, Ahvaz Jundishapur University of Medical Sciences, Ahvaz, IR Iran \\ "Corresponding author: Saeed Shirali, Department of Laboratory Sciences, Hyperlipidemia Research Center, Ahvaz Jundishapur University of Medical Sciences, Ahvaz, IR Iran. \\ Tel: +98-6113738317, Fax: +98-6113738330, E-mail: saeed.shirali@gmail.com
}

Received 2015 July 20; Revised 2016 June 19; Accepted 2016 July 24.

\begin{abstract}
Context: Diabetes mellitus is the most common endocrine disease worldwide and its prevalence is increasing. The development of drugs with fewer side-effects is required when treating this disease. Thus, the objective of this study was to evaluate the use of traditional medicine and medicinal plants in this regard. The various mechanisms by which isolated extracts and herbal compounds exert their effects on different diabetes mellitus factors was investigated.

Evidence Acquisition: Databases such as PubMed, Science Direct, and Web of Science (from 1990 until the present) were searched, using a detailed list of terms related to the effects and mechanism of herbal ingredients on diabetes mellitus complications.

Results: The presence of secondary metabolites, such as phenols, flavonoids and alkaloids in plants, have been used as a source of medication for the treatment of many diseases, including diabetes mellitus. Following an extensive review of the literature, it was found that the secondary metabolites of plants have a wide range of anti-diabetic effects.

Conclusions: Plant compounds should be isolated and their effects on diabetes mellitus and its complications examined in order to treatment for diabetes mellitus.
\end{abstract}

Keywords: Diabetes Complications, Diabetes Mellitus, Flavonoids, Mechanism, Phenols

\section{Context}

Diabetes mellitus is one of the most common diseases in the world. It is due to either the pancreas not producing enough insulin or the cells of the body not responding properly to the insulin produced. The disease has a considerable economic and social impact (1). In 2009, diabetes mellitus was ranked as the fifth cause of death worldwide and its prevalence increases every day (2). In 2010, it was reported that the number of 20- to 69-year-old people with diabetes mellitus equated to 285 million and it was estimated that this number would reach 439 million in 2030 (3). A poor lifestyle, lack of exercise, eating high-fat food, and obesity are risk factors for the development of diabetes mellitus. It is estimated that in regions such as Asia and Africa, the rate of diabetes mellitus is two or three times more than that in other areas (4).

An increased blood glucose through the involvement of the polyol pathway and sorbitol production, the production of protein glycosylation [advanced glycation end products (AGE)], a reduction in nitric oxide (NO) production, and the activation of protein kinase $C$ leads to neuropathy, nephropathy retinopathy, and cardiovascular disease (5). In addition, hyperglycemia stimulates the production of reactive oxygen species and the extension of oxidative reactions (6). Exercising, changing to healthier eating habits, and the use of glucose-lowering drugs can reduce complications of this disease (7).

Herbal medicinal compounds are used worldwide owing to the perception that they are less toxic than mainstream drugs. Thus, there is incentive to use them to treat various diseases (8). In response to demands for the inclusion of compounds from medicinal plants in medications, manufacturers of these products have had to ensure the addition of high-quality extracts using optimal separation methods (9).

Plant compounds can influence the biological pathways associated with diabetes mellitus complications. However, this is a previously held view and one that is not necessarily held in the present. Plant compounds, such as Galega officinalis L, have previously been used to treat low blood sugar and diabetes mellitus. Metformin was obtained from this plant (10).

Although the effect and mechanism of most plants compounds in diabetes mellitus treatment has not been adequately identified, but their effects can be by glucose intestinal absorption, metabolic insulin-dependent processes, and the antioxidant effects of these processes $(11,12)$. Here, the effects and mechanisms of isolated extracts and plant compounds on different factors of diabetes mellitus were reviewed investigated in this paper. 


\section{Evidence Acquisition}

Plants were classified according to their mechanism of action in this study. For this purpose, databases such as PubMed, Science Direct, and Web of Science were used, in conjunction with a detailed list of terms that related to the effect and mechanism of herbal ingredients on diabetes mellitus complications. Thereafter, The content of 80 articles was studied.

\section{Results}

\subsection{The Role of Antioxidants}

Oxidative stress occurs due to an imbalance between the production of free radicals and the antioxidant system. An increase in free radicals damages the cellular components. A long-term increase in blood glucose leads to the imbalance that is found in diabetes mellitus (13). Glucose is able to oxidized automatically and can bind to proteins non-enzymatically, resulting in the formation of AGEs or polyol pathway involvement, together with the activation of aldose reductase. Ultimately, it results in the depletion of nicotinamide adenine dinucleotide phosphate and an increase in nicotinamide adenine dinucleotide. In addition, hyperglycemia occurring during diabetes mellitus leads to an increase in NO synthase and xanthine oxidase activity (14).

Crocus sativum contains compounds, such as carotenoids, one of which is crocin, an antioxidant, which could be used in the treatment of diabetes mellitus as its potential has been demonstrated in various studies. The effect of crocin on diabetic rats was investigated and it was shown that it caused a significant reduction in blood glucose, lipid profile, and glycated hemoglobin (15). The anti-diabetic effect of saffron was also confirmed in another study, probably owing to its antioxidant properties (16).

It was demonstrated in a study by Barari et al. that the antioxidant properties of a substance in milk thistle (Silybum marianum), especially a flavonoid called silymarin, were reduced by inflammatory agents such as tumor necrosis factor- $\alpha$ and interleukin-6 (17). To evaluate the antioxidant effect of silymarin, it was injected into alloxan-induced diabetic rats. Superoxide dismutase, glutathione peroxidase, and catalase activity was examined at the end of the treatment period and the results showed a significant increase in the enzyme activity therein. Thus, silymarin plays an important role in the body's defense against free radicals (18). Antioxidants, useful in treating diabetes mellitus, are found in green and sour tea.

The effects of antioxidants on patients with type $2 \mathrm{di}$ abetes mellitus were examined in another study. It was shown following an evaluation of factors such as blood glucose, insulin, lipid profile, and antioxidant levels, that both plants were effective in reducing antioxidant levels and the lipid profile (19).

Celery (Apium graveolens) is an antioxidant herb and contains flavonoids, such as apigenin and apiin. The antioxidant properties of this herb lead to an increase in the fertility and improvement of sperm performance (20, 21). It was shown that the antioxidant activity of hydroalcoholic leaf extract of celery decreased the lipid profile in rats on a high-fat diet (20). It was also reported in another study (22) that a reduction in blood glucose and activity increased the enzyme activity of superoxide dismutase, catalase, and glutathione reductase. However, a significant increase in alanine transaminase and aspartate transaminase levels in diabetic rats treated with n-butanol extract of celery was not found (22).

\subsection{Effect on Adiponectin Releasing}

As an endocrine tissue, adipose tissue plays a role in energy balance in the body through the release of active ingredients, such as resistin, adipsin, leptin, and adiponectin (23). Two human adiponectin receptors are found in the skeletal muscles. They intermediate the effect of globular and full-length adiponectin. An increase in the expression of these receptors is associated with an increase in insulin sensitivity (24). Adiponectin affects the gluconeogenesis process and fatty acid oxidation through 5' adenosine monophosphate-activated protein kinase (AMP)-dependent protein kinase and peroxisome proliferator-activated receptor (PPAR) in the liver. Moreover, it increases glucose uptake in the peripheral tissues and stimulates insulin secretion, ultimately leading to a regulation of the body's energy (25). The interaction between adiponectin and adapter proteins, such as adaptor protein containing $\mathrm{PH}$ domain, phosphotyrosinebinding domain, and leucine zipper, is important in the adiponectin signaling pathway and for an increase in insulin sensitivity (26).

The biological activity of flavonoids is frequent and it has been observed that they are effective in adiponectin secretion from the adipose tissue (27). Tiliroside increases the level of serum adiponectin in obese-diabetic (KK-Ay) mice (28). It was confirmed in a study on the aqueous and hydro-alcoholic extracts of Momordica charantia that an aqueous extract at a concentration of $0.2 \mathrm{mg} / \mathrm{mL}$, along with $0.5 \mathrm{nM}$ insulin, increased glucose absorption (61\%) and adiponectin secretion (75\%) in the 3T3-L1 cells, while 0.4 $\mathrm{mg} / \mathrm{mL}$ of ethanol extract increased glucose uptake only in the presence of $50 \mathrm{nM}$ insulin. In fact, the compounds of aqueous extract are effective in adiponectin secretion and glucose uptake in very low insulin concentrations (29). 
Ginseng has many therapeutic properties owing to the presence of compounds, such as saponins and ginsenosides. For example, American ginseng or Panax quinquefolius contains ginsenosides, such as Rb1 and Rb2 (30). American ginseng acts as a glucose-reducing agent in patients with type 2 diabetes mellitus (31). It was indicated in a study on American ginseng that it led to an increase in the expression of adiponectin and a reduction in lipid accumulation in the 3T3-L1 cells (32).

\subsection{The Enhancement of Glucose Uptake Through the Upregu- lation of Glucose Transporter Type 4}

Glucose is transported into cells by a large family of transporters called glucose transporters (GLUT) of which there are different types, such as glucose transporter type 4 (GLUT4), which is regulated by insulin and is found in the skeletal muscles and adipose tissue (33). The overexpression of GLUT4 was shown to be important in reducing blood glucose and its absorption into the muscles and adipose tissue in animal models of diabetes mellitus (C57BL/KsJ-db/db mice) (34).

Berberine is an isoquinoline alkaloid that is found in plants, such as Berberis vulgaris and B. aristata, leading to the translocation of GLUT4 and an increase in 3T3-L1 adipocytes and L6 myotubes (35). Naowaboot et al. examined the effect of Morus alba L. leaf as an anti-hyperglycemic agent. The results showed that glucose uptake increased in the adipocytes. Also, this effect was confirmed when wortmannin, as an inhibitor of phosphoinositide-3-kinase (P13K) and GLUT4 translocation, was used (36).

It was shown in a study that Cinnamomum zeylanicum increased adipocyte growth, decreased adipolysis and increased the entry of glucose into the 3T3-L1 cells. Therefore, it is very effective in blood glucose homeostasis. Also, it was observed in other research that the consumption of cinnamon extract resulted in GLUT4 translocation from the smooth endoplasmic reticulum membranes to the cytoplasm in the $\mathrm{C} 2 \mathrm{C} 12$ cells and that it was effective in energy homeostasis (37).

The Ficus spp. have different therapeutic effects, including anti-diabetic properties. A study of the effects of 10 species of this genus on glucose metabolism indicated that only the species, F. lutea, has an anti-diabetic effect because its leaf extract affects blood glucose uptake in the peripheral tissue and causes a reduction in blood glucose concentration which is probably due to its influence on GLUT4 (38).

The researchers studied the effects of Panax ginseng on the 3T3-L1cells. They found that the active ingredients in this plant, such as ginsenosides Rg3 and Re, were effective with respect to glucose uptake via insulin-dependent pathways because it increased the expression of GLUT4, insulin receptor substrate 1 , and PI3K (39).

Epigallocatechin gallate (ECCG) is a flavonoid that is found in green tea and is active biologically. This compound is used to treat various diseases, including obesity. The inhibition of glucose uptake and a reduction in GLUT4 in the cell surfaces through the insulin-like growth factor (IGF)-I and IGF-II pathways and 67-kDa laminin receptor were demonstrated following an evaluation of its effects on the 3T3-L1 adipocytes. Interestingly, it was increased glucose uptake via GLUT1 (40).

\subsection{The Inhibition of Glucose Absorption}

Alpha-amylase is secreted from the pancreas and salivary glands, leading to the conversion of starch into maltose, a substrate required for $\alpha$-glucosidase enzyme activity. Alpha-amylase is located in the brush-border membrane of the intestinal epithelial cells, leading to the hydrolysis of disaccharide into monosaccharide (41, 42). Glucose is a most important monosaccharide in the intestine and is unable to cross the lipid membrane of cells into the small intestine. This work acts through a Na-dependent glucose transporter (43). An increase in blood glucose following a meal is an early indicator of energy homeostasis impairment and indicates the need for diabetes mellitus treatment (44). Hyperglycemia occurs after a meal owing to increased $\alpha$-amylase and $\alpha$-glucosidase activity. Therefore, inhibitors of these enzymes might be helpful in moderating blood sugar levels. However, the most commonly used enzyme inhibitors, including acarbose and miglitol, have side-effects, such as abdominal pain and diarrhea (45).

Flavonoids are effective compounds for glucose absorption in the small intestine. It was indicated in a kinetic study on the effects of flavonoid compounds, such as quercetin-3-glucoside (isoquercitrin) and quercetin-4'glucoside (spiraeosid), on the inhibition of glucose uptake, that these compounds, such as sodium-dependent glucose co-transporter(SGLT)-1 competitive inhibitors, prevented the absorption of methyl $\alpha$-D-glucopyranoside (non-metabolizable glucose analogue), while the aglycone forms did not affect glucose absorption (46).

Phlorizin, a type of flavonoid belonging to the isosalipurposide dihydrochalcone group, is found in fruits, such as apples, and could be used in the treatment of type II diabetes mellitus because it reduced SGLT-1 expression and blood glucose levels in diabetic rats (47).

It was shown following an evaluation of the effects of different extracts prepared from the root of Devil's cotton on the activity of purified $\alpha$-D-glucosidase from 
Sacharomyces cerevisiae that only the petroleum ether extract from this plant had a significant effect on the inhibition of this enzyme in vitro and could be used in the composition of diabetes mellitus medication (48).

It was indicated after an assessment of the antioxidant activity of aqueous and methanol extracts prepared from the bark, leaf, and root of mahogany (Khaya), that only the root extract had antioxidant activity. In addition, the effect of this extract on the kinetics of the $\alpha$-glucosidase and $\alpha$-amylase enzymes was shown to be a competitive inhibitory one for $\alpha$-glucosidase and a non-competitive inhibitory one for $\alpha$-amylase (49).

The effects of fenugreek seed extracts on glucose absorption in the small intestine were examined and it was reported that saponin- and sapogenin-rich extracts had a higher effect on glucose absorption than other extracts (50).

The soybean (Glycine max) is a plant in the Fabaceae family that has anti-diabetic properties. It was demonstrated that rich extracts of polyphenols and free phenol had an inhibitory effect on $\alpha$-amylase and $\alpha$-glucosidase. Therefore, they can be used as effective compounds in the treatment of diabetes mellitus (51).

The effects of Guduchi (Tinospora cordifoliaon) leaf extracts on $\alpha$-amylase activity were examined and it was demonstrated that they inhibited $\alpha$-amylase enzyme activity (52). It was also shown in a study on green tea poly phenols that compounds, such as epicatechin gallate and EGCG, acted as competitive inhibitors of SGLT- 1 in the small intestine in rabbits (53).

\subsection{Other Mechanisms}

In addition to the previously described mechanisms, there are other ways in which to control diabetes mellitus. These are now described. Following an examination on the effects of an ethanol extract prepared from the bark of Yuzu (Citrus junos Tanaka), it was shown that it was effective in regulating glucose uptake and AMPK activity in the $\mathrm{C} 2 \mathrm{C} 12$ cells in mice on a high-fat $\operatorname{diet}(54)$.

Wax gourd (Benincasa hispida), derived from the $\mathrm{Cu}-$ curbitaceae family, is used in East Asia to treat obesity. Following an examination of its effect on C57BL6 mice, it was confirmed that it decreased PPAR- $\gamma$ and 3-hydroxy3-methylglutaryl-CoA reductase expression and improved the lipid profile, resulting in fasting glucose reduction(55).

Loquat (Eriobotrya japonica) is a plant in the Rosaceae family. Its aqueous extract is effective in reducing blood sugar through its effect on the pancreas beta cells. Following the isolation of compounds from this extract, it was shown that cinchonain Ib led to insulin secretion from the INS-1 cells after 240 minutes (56). It was shown in a study that the use of methanol extract of Ocimum sanctum significantly reduced blood sugar levels by reducing the number of key enzymes in the carbohydrate metabolism pathway (glucokinase, hexokinase, and phosphofructokinase). It also increased glycogen content in the kidney and decreased it in the liver and skeletal muscles (57). It was shown in a study on Dong Quai Japanese (Angelica acutiloba) that this herb was effective in reducing insulin resistance. Its root extract decreased the expression of phosphoenolpyruvate carboxykinase and resulted in a reduction in gluconeogenesis pathway activity in the liver, while it increased glycogen content in the liver (58). In addition, following an examination of 13 pentacyclic triterpenoids isolated from the methanol extract of common self-heal (Prunella vulgaris L.), it was shown that these compounds had variable degrees of glycogen phosphorylase inhibition (an IC50 range of $30.69-68.85 \mu \mathrm{M}$ (59).

Glucagon-like peptide (GLP)-1 is an endocrine hormone produced by the enteroendocrine L cells and stimulates beta cell growth, synthesis, secretion, the release of insulin, and glucagon secretion inhibition. It was confirmed in a study on the aqueous extract of wild bitter gourd (Momordica charantia) that it led to an increase in GLP-1 and a significant reduction in blood glucose 30 seconds after its administration. In addition, the use of a GLP-1 receptor antagonist, such as exendin-9, decreased hypoglycemia (60). Stereoisomerically, there are nine inositol isomers, of which d-chiro-inositol isomer is very rare and is found in plants. In addition, it is found in the structure of inositol phosphoglycan and is important in the insulin signaling pathway (61). It plays as an anti-hyperglycemic role in the insulin signaling pathway (62). Cucurbit aficifolia is a rich source of d-chiro-inositol and is used as a treatment for diabetes mellitus in the Asian region. The consumption of the methanol extract of the Cucurbita ficifolia fruit was found to reduce blood sugar and increase total hemoglobin, insulin, and liver glycogen, comparable to the effects of synthetic d-chiro-inositol (63). The use of soluble fiber, such as ß-glucan, can be used to treat diabetes mellitus. It is very effective in combatting hyperglycemia after a meal because it prevents sugar absorption. The effect of polysaccharides prepared from Rhynchelytrum repens on blood glucose levels in diabetic rats was examined in a study and it was reported that they significantly decreased them. Furthermore, the presence of high ß-glucan levels was confirmed after hydrolyzing the fresh leaves of $R$. repens with endo-ß glucanase and conducting high-performance liquid chromatography analysis (64).

\section{Conclusion}

The effects and mechanism of plant compounds and extracts on a reduction in diabetes mellitus complications 
was investigated in this study. It was found that plant compounds and extracts can be used as anti-diabetic agents (Table 1) as many of them have antioxidant properties (such as celery), recommended in reducing hyperglycemia complications, while others (such as soybeans) are effective in lowering blood sugar through the inhibition of glucose uptake subsequent to a meal. Some plants are effective through several mechanisms. For example, American ginseng increases adiponectin expression and also leads to an increment in GLUT4 at the cell surface.

Finally, it was indicated in this study that secondary metabolites of plants have a wide range of effects on diabetes mellitus treatment. Therefore, plant compounds should be separated and their individual effects on diabetes mellitus examined.

\section{Footnote}

Funding/Support: Financial support for the present study was received from the student research committee, Ahvaz Jundishapur University of Medical Sciences, Ahvaz, Iran.

\section{References}

1. Bathaie SZ, Mokarizade N, Shirali S. An overview of the mechanisms of plant ingredients in the treatment of diabetes mellitus.J Med Plants. 2012;4(44):1-24.

2. Jayaraman R, Shivakumar A, Anitha T, Joshi VD, Palei NN. Antidiabetic effect of petroleum ether extract of Citrullus colocynthis fruits against streptozotocin-induced hyperglycemic rats. Rom J Biol Plant Biol. 2009;4:127-34.

3. Azahari N, Khattak MMAK, Taher M, Ichwan SJA. Dose Water Extract of Cinnamon (Cinnamomum Zeylanicum) Exhibits Anti-Diabetic Properties in Cultured 3T3-L1 Adipocytes: A Concurrent Assessment of Adipogenesis, Lipolysis and Glucose Uptakes. J Food Nutr Res. 2014;2(11):764-9.

4. Eidi A, Eidi M, Sokhteh M. Effect of fenugreek (Trigonella foenum-graecum L) seeds on serum parameters in normal and streptozotocin-induced diabetic rats. Nutr Res. 2007;27(11):728-33.

5. Akinmoladun AC, Farombi EO, Oguntibeju OO. Antidiabetic botanicals and their potential benefits in the management of diabetes mellitus. Antioxidant Antidiabe Agents Human Health Intech Croatia. 2014;6:139-64.

6. Iweala EEJ, Uhegbu FO, Adesanoye OA. Biochemical effects of leaf extracts of Gongronema latifolium and selenium supplementation in alloxan induced diabetic rats. J Pharm Phytother. 2013;5(5):91-7.

7. Morphy R, Kay C, Rankovic Z. From magic bullets to designed multiple ligands. Drug Discov Today. 2004;9(15):641-51. doi: 10.1016/S13596446(04)03163-0. [PubMed: 15279847].

8. Ayyanar M, Sankarasivaraman K, Ignacimuthu S. Traditional herbal medicines used for the treatment of diabetes among two major tribal groups in south Tamil Nadu, India. Ethnobotanical Leaflets. 2008;2008(1):32.

9. Pashazanousi MB, Raeesi M, Shirali S. Chemical composition of the essential oil, antibacterial and antioxidant activities, total phenolic and flavonoid evaluation of various extracts from leaves and fruit peels of Citrus limon. Asian J Chem. 2012;24(10):4331.
10. El-Abhar HS, Schaalan MF. Phytotherapy in diabetes: review on potential mechanistic perspectives. World J Diabetes. 2014;5(2):176-97.

11. El-Soud NHA, Khalil MY, Hussein JS, Oraby FSH, Farrag ARH. Antidiabetic effects of fenugreek alkaloid extract in streptozotocin induced hyperglycemic rats. J Appl Sci Res. 2007;3(10):1073-83.

12. Mooradian AD, Lung CC, Pinnas JL. Glycosylation enhances malondialdehyde binding to proteins. Free Radic Biol Med. 1996;21(5):699-701. [PubMed: 8891672].

13. Rahimi R, Nikfar S, Larijani B, Abdollahi M. A review on the role of antioxidants in the management of diabetes and its complications. Biomed Pharmacother. 2005;59(7):365-73. doi: 10.1016/j.biopha.2005.07.002. [PubMed: 16081237].

14. Martin-Gallan P, Carrascosa A, Gussinye M, Domínguez C. Biomarkers of diabetes-associated oxidative stress and antioxidant status in young diabetic patients with or without subclinical complications. Free Radical Biol Med. 2003;34(12):1563-74.

15. Shirali S, Zahra Bathaie S, Nakhjavani M. Effect of crocin on the insulin resistance and lipid profile of streptozotocin-induced diabetic rats. Phytother Res. 2013;27(7):1042-7. doi: 10.1002/ptr.4836. [PubMed: 22948795].

16. Shirali S, Bathaei SZ, Nakhjavani M, Ashoori MR. Effects of saffron (Crocus Sativus L.) aqueous extract on serum biochemical factors in streptozotocin-induced diabetic rats. Iran J Med Arom Plants. 2012;28(2):293-08.

17. Barari AR, Alavi SH, Shirali S, Ghazalian F. Effect of short-term endurance training and silymarin consumption on some of preinflammatory cytokines, growth mediators and immune system performance. Ann Biol Res. 2012;3(6):2933-7.

18. Soto C, Recoba R, Barron H, Alvarez C, Favari L. Silymarin increases antioxidant enzymes in alloxan-induced diabetes in rat pancreas. Comp Biochem Physiol C Toxicol Pharmacol. 2003;136(3):205-12. [PubMed: 14659454].

19. Mozaffari-Khosravi H, Ahadi Z, Fallah Tafti M. The Effect of Green Tea versus Sour Tea on Insulin Resistance, Lipids Profiles and Oxidative Stress in Patients with Type 2 Diabetes Mellitus: A Randomized Clinical Trial. Iran J Med Sci. 2014;39(5):424-32. [PubMed: 25242840].

20. Kooti W, Ghasemiboroon M, Asadi-Samani M, Ahangarpoor A, Abadi MNA, Afrisham R, et al. The effects of hydro-alcoholic extract of celery on lipid profile of rats fed a high fat diet. Adv Environ Biol. 2014:325-31.

21. Kooti W, Mansouri E, Ghasemiboroon M, Harizi M, Ashtary-Larky D, Afrisham R. The Effects of Hydroalcoholic Extract of Apium graveolens Leaf on the Number of Sexual Cells and Testicular Structure in Rat. Jundishapur J Nat Pharm Prod. 2014;9(4):ee17532. [PubMed: 25625050].

22. Al-Sa'aidi JAA, Alrodhan MNA, Ismael AK. Antioxidant activity of nbutanol extract of celery (Apium graveolens) seed in streptozotocininduced diabetic male rats. Res Pharm Biotechnol. 2012;4(2):24-9.

23. Kadowaki T, Yamauchi T. Adiponectin and adiponectin receptors. Endocr Rev. 2005;26(3):439-51. doi: 10.1210/er.2005-0005. [PubMed: 15897298].

24. Stefan N, Machicao F, Staiger H, Machann J, Schick F, Tschritter O, et al. Polymorphisms in the gene encoding adiponectin receptor 1 are associated with insulin resistance and high liver fat. Diabetologia. 2005;48(11):2282-91. doi: 10.1007/s00125-005-1948-3. [PubMed: 16205883].

25. Li S, Shin HJ, Ding EL, van Dam RM. Adiponectin levels and risk of type 2 diabetes: a systematic review and meta-analysis. JAMA. 2009;302(2):179-88. doi:10.1001/jama.2009.976. [PubMed: 19584347].

26. Kadowaki T, Yamauchi T, Kubota N, Hara K, Ueki K, Tobe K. Adiponectin and adiponectin receptors in insulin resistance, diabetes, and the metabolic syndrome. J Clin Invest. 2006;116(7):1784-92. doi: 10.1172/JCI29126. [PubMed: 16823476].

27. Hassan M, El Yazidi C, Landrier JF, Lairon D, Margotat A, Amiot MJ. Phloretin enhances adipocyte differentiation and adiponectin expression in 3T3-L1 cells. Biochem Biophys Res Commun. 2007;361(1):20813. doi:10.1016/j.bbrc.2007.07.021. [PubMed: 17658475]. 
28. Goto T, Teraminami A, Lee JY, Ohyama K, Funakoshi K, Kim YI, et al. Tiliroside, a glycosidic flavonoid, ameliorates obesity-induced metabolic disorders via activation of adiponectin signaling followed by enhancement of fatty acid oxidation in liver and skeletal muscle in obese-diabetic mice. J Nutr Biochem. 2012;23(7):768-76. doi: 10.1016/j.jnutbio.2011.04.001. [PubMed: 21889885].

29. Roffey BW, Atwal AS, Johns T, Kubow S. Water extracts from Momordica charantia increase glucose uptake and adiponectin secretion in 3T3-L1 adipose cells. J Ethnopharmacol. 2007;112(1):77-84. doi: 10.1016/j.jep.2007.02.003. [PubMed: 17363205].

30. Wang A, Wang CZ, Wu JA, Osinski J, Yuan CS. Determination of major ginsenosides in Panax quinquefolius (American ginseng) using high-performance liquid chromatography. Phytochem Anal. 2005;16(4):272-7. [PubMed: 16042154].

31. Vuksan V, Sievenpiper JL, Koo VY, Francis T, Beljan-Zdravkovic U, Xu Z, et al. American ginseng (Panax quinquefolius $\mathrm{L}$ ) reduces postprandial glycemia in nondiabetic subjects and subjects with type 2 diabetes mellitus. Arch Intern Med. 2000;160(7):1009-13. [PubMed: 10761967].

32. Yeo CR, Lee SM, Popovich DG. Ginseng (Panax quinquefolius) Reduces Cell Growth, Lipid Acquisition and Increases Adiponectin Expression in 3T3-L1 Cells. Evid Based Complement Alternat Med. 2011;2011:610625. doi: 10.1093/ecam/neq051. [PubMed: 21799682].

33. Furtado LM, Somwar R, Sweeney G, Niu W, Klip A. Activation of the glucose transporter GLUT4 by insulin. Biochem Cell Biol. 2002;80(5):56978. [PubMed: 12440698].

34. Gibbs EM, Stock JL, McCoid SC, Stukenbrok HA, Pessin JE, Stevenson $\mathrm{RW}$, et al. Glycemic improvement in diabetic $\mathrm{db} / \mathrm{db}$ mice by overexpression of the human insulin-regulatable glucose transporter (GLUT4).JClin Invest. 1995;95(4):1512-8. doi: 10.1172/JCI117823. [PubMed: 7706456].

35. Lee YS, Kim WS, Kim KH, Yoon MJ, Cho HJ, Shen Y, et al. Berberine, a natural plant product, activates AMP-activated protein kinase with beneficial metabolic effects in diabetic and insulin-resistant states. Diabetes. 2006;55(8):2256-64. doi: 10.2337/db06-0006. [PubMed: 16873688].

36. Naowaboot J, Pannangpetch P, Kukongviriyapan V, Prawan A, Kukongviriyapan U, Itharat A. Mulberry leaf extract stimulates glucose uptake and GLUT4 translocation in rat adipocytes. Am J Chin Med. 2012;40(1):163-75. doi: 10.1142/S0192415X12500139. [PubMed: 22298456].

37. Absalan A, Mohiti-Ardakani J, Hadinedoushan H, Khalili MA. HydroAlcoholic Cinnamon Extract, Enhances Glucose Transporter Isotype4 Translocation from Intracellular Compartments into the Cytoplasmic Membrane of $\mathrm{C} 2 \mathrm{C} 12$ Myotubes. Indian J Clin Biochem. 2012;27(4):351-6. doi: 10.1007/s12291-012-0214-y. [PubMed: 24082459].

38. Olaokun OO, McGaw LJ, Awouafack MD, Eloff JN, Naidoo V. The potential role of GLUT4 transporters and insulin receptors in the hypoglycaemic activity of Ficus lutea acetone leaf extract. BMC Complement Altern Med. 2014;14:269. doi: 10.1186/1472-6882-14-269. [PubMed: 25070239].

39. Lee $\mathrm{OH}$, Lee $\mathrm{HH}$, Kim JH, Lee BY. Effect of ginsenosides Rg3 and Re on glucose transport in mature 3T3-L1 adipocytes. Phytother Res. 2011;25(5):768-73. doi: 10.1002/ptr.3322. [PubMed: 21520470].

40. Ku HC, Tsuei YW, Kao CC, Weng JT, Shih LJ, Chang HH, et al. Green tea (-)-epigallocatechin gallate suppresses IGF-I and IGF-II stimulation of 3T3-L1 adipocyte glucose uptake via the glucose transporter 4, but not glucose transporter 1 pathway. Gen Comp Endocrinol. 2014;199:46-55. doi: 10.1016/j.ygcen.2014.01.008. [PubMed: 24486085].

41. Loizzo MR, Saab AM, Tundis R, Menichini F, Bonesi M, Piccolo V, et al. In vitro inhibitory activities of plants used in Lebanon traditional medicine against angiotensin converting enzyme (ACE) and digestive enzymes related to diabetes. I Ethnopharmacol. 2008;119(1):10916. doi: 10.1016/j.jep.2008.06.003. [PubMed:18601990].

42. Kam A, Li KM, Razmovski-Naumovski V, Nammi S, Shi J, Chan K, et al A comparative study on the inhibitory effects of different parts and chemical constituents of pomegranate on alpha-amylase and alpha- glucosidase. Phytother Res. 2013;27(11):1614-20. doi: 10.1002/ptr.4913. [PubMed: 23280757].

43. Nistor Baldea LA, Martineau LC, Benhaddou-Andaloussi A, Arnason JT, Levy E, Haddad PS. Inhibition of intestinal glucose absorption by anti-diabetic medicinal plants derived from the James Bay Cree traditional pharmacopeia. J Ethnopharmacol. 2010;132(2):473-82. doi: 10.1016/j.jep.2010.07.055. [PubMed: 20804840].

44. Hou W, Li Y, Zhang Q, Wei X, Peng A, Chen L, et al. Triterpene acids isolated from Lagerstroemia speciosa leaves as alpha-glucosidase inhibitors. Phytother Res. 2009;23(5):614-8. doi: 10.1002/ptr.2661. [PubMed: 19107840].

45. Bhat M, Zinjarde SS, Bhargava SY, Kumar AR, Joshi BN. Antidiabetic Indian plants: a good source of potent amylase inhibitors. Evid Based Complement Alternat Med. 2011;2011:810207. doi: 10.1093/ecam/nen040. [PubMed: 18955350].

46. Ader P, Block M, Pietzsch S, Wolffram S. Interaction of quercetin glucosides with the intestinal sodium/glucose co-transporter (SGLT-1). Cancer Lett. 2001;162(2):175-80. [PubMed: 11146223].

47. Masumoto S, Akimoto Y, Oike H, Kobori M. Dietary phloridzin reduces blood glucose levels and reverses Sglt1 expression in the small in testine in streptozotocin-induced diabetic mice. J Agric Food Chem. 2009;57(11):4651-6. doi: 10.1021/jf9008197. [PubMed: 19413312]

48. Bisht R, Bhattacharya S, Jaliwala YA. Evaluating the use of root extract of Abroma augusta as alpha glucosidase inhibitor for Type-II diabetes. Ann Plant Sci. 2014;3(04):686-91.

49. Ibrahim MA, Koorbanally NA, Islam MS. Antioxidative activity and inhibition of key enzymes linked to type-2 diabetes (alphaglucosidase and alpha-amylase) by Khaya senegalensis. Acta Pharm. 2014;64(3):311-24. doi: 10.2478/acph-2014-0025. [PubMed: 25296677].

50. Al-Habori M, Raman A, Lawrence M], Skett P. In vitro effect of fenugreek extracts on intestinal sodium-dependent glucose uptake and hepatic glycogen phosphorylase A. Int J Exp Diabetes Res. 2001;2(2):919. [PubMed: 12369721].

51. Ademiluyi AO, Oboh G. Soybean phenolic-rich extracts inhibit key-enzymes linked to type 2 diabetes (alpha-amylase and alpha-glucosidase) and hypertension (angiotensin I converting enzyme) in vitro. Exp Toxicol Pathol. 2013;65(3):305-9. doi: 10.1016/j.etp.2011.09.005. [PubMed: 22005499].

52. Shareef MI, Reddy PJM, Gopinath SM, Dayananda KS, Mandal A. In vitro $\alpha$ amylase inhibitory activity of the leaves of Tinospora cordifolia. Int J Innovat Res Scie Engin Technol. 2014;3(3):10091-6.

53. Kobayashi Y, Suzuki M, Satsu H, Arai S, Hara Y, Suzuki K, et al. Green tea polyphenols inhibit the sodium-dependent glucose transporter of intestinal epithelial cells by a competitive mechanism. J Agric Food Chem. 2000;48(11):5618-23. [PubMed:11087528].

54. Kim SH, Hur HJ, Yang HJ, Kim HJ, Kim MJ, Park JH, et al. Citrus junos Tanaka Peel Extract Exerts Antidiabetic Effects via AMPK and PPAR-gamma both In Vitro and In Vivo in Mice Fed a HighFat Diet. Evid Based Complement Alternat Med. 2013;2013:921012. doi: 10.1155/2013/921012. [PubMed: 23762167].

55. Gu M, Fan S, Liu G, Guo L, Ding X, Lu Y, et al. Extract of Wax Gourd Peel Prevents High-Fat Diet-Induced Hyperlipidemia in C57BL/6 Mice via the Inhibition of the PPARgamma Pathway. Evid Based Complement Alternat Med. 2013;2013:342561. doi: 10.1155/2013/342561. [PubMed: 23533476].

56. Qa'dan F, Verspohl EJ, Nahrstedt A, Petereit F, Matalka KZ. Cinchonain Ib isolated from Eriobotrya japonica induces insulin secretion in vitro and in vivo. J Ethnopharmacol. 2009;124(2):224-7. doi: 10.1016/j.jep.2009.04.023. [PubMed:19397981].

57. Vats V, Yadav SP, Grover JK. Ethanolic extract of Ocimum sanctum leaves partially attenuates streptozotocin-induced alterations in glycogen content and carbohydrate metabolism in rats. J Ethnopharmacol. 2004;90(1):155-60. [PubMed:14698524].

58. Liu IM, Tzeng TF, Liou SS, Chang CJ. Angelica acutiloba root attenuates insulin resistance induced by high-fructose diet in rats. Phytother Res. 
2011;25(9):1283-93. doi: 10.1002/ptr.3403. [PubMed: 21308821].

59. Yu Q, Qi J, Wang L, Liu SJ, Yu BY. Pentacyclic triterpenoids from spikes of Prunella vulgaris L. inhibit glycogen phosphorylase and improve insulin sensitivity in 3T3-L1 adipocytes. Phytother Res. 2015;29(1):73-9. doi: 10.1002/ptr.5228. [PubMed: 25278372].

60. Huang TN, Lu KN, Pai YP, Chin H, Huang CJ. Role of GLP-1 in the Hypoglycemic Effects of Wild Bitter Gourd. Evid Based Complement Alternat Med. 2013;2013:625892. doi: 10.1155/2013/625892. [PubMed: 23589719].

61. Horbowicz M, Brenac P, Obendorf RL. Fagopyritol B1, O-alphaD-galactopyranosyl-(1->2)-D-chiro-inositol, a galactosyl cyclitol in maturing buckwheat seeds associated with desiccation tolerance. Planta. 1998;205(1):1-11. [PubMed: 9599801].

62. Fonteles MC, Huang LC, Larner J. Infusion of pH 2.0 D-chiro-inositol glycan insulin putative mediator normalizes plasma glucose in streptozotocin diabetic rats at a dose equivalent to insulin without inducing hypoglycaemia. Diabetologia. 1996;39(6):731-4. [PubMed: 8781770].

63. Xia T, Wang Q. D-chiro-inositol found in Cucurbita ficifolia (Cucurbitaceae) fruit extracts plays the hypoglycaemic role in streptozocin-diabetic rats. J Pharm Pharmacol. 2006;58(11):1527-32. doi: 10.1211/jpp.58.10.0014. [PubMed: 17132216].

64. De Paula AC, Sousa RV, Figueiredo-Ribeiro RC, Buckeridge MS. Hypoglycemic activity of polysaccharide fractions containing betaglucans from extracts of Rhynchelytrum repens (Willd.) C.E. Hubb., Poaceae. Braz J Med Biol Res. 2005;38(6):885-93. [PubMed: 15933782]. 
Table 1. The Effect Mechanism of Plants in Treatment of Diabetes Mellitus

\begin{tabular}{|c|c|c|c|c|}
\hline Reference & Plant & Family & Extract or Compound & Description of Effect(s) \\
\hline Shirali et al. (15) & Saffron (Crocus sativus) & Iridaceae & Crocin & $\begin{array}{l}\text { An improvement in glucose, lipid } \\
\text { profile, and HbA1c levels }\end{array}$ \\
\hline Soto et al. (18) & Milk thistle (Silybum marianum) & Asteraceae & Silymarin & $\begin{array}{l}\text { An increase in SOD, CAT, and GSH-Px } \\
\text { activity }\end{array}$ \\
\hline Al-Sa'aidi et al. (22) & Celery (Apium graveolens) & Apiaceae & n-butanol & $\begin{array}{l}\text { A hypoglycemia effect and an } \\
\text { increase in SOD, GSH reductase, GSH } \\
\text { transferase, and CAT }\end{array}$ \\
\hline Yeo et al. (32) & $\begin{array}{l}\text { American ginseng (Panax } \\
\text { quinquefolius) }\end{array}$ & Araliaceae & Methanol & $\begin{array}{l}\text { An increase in adiponectin } \\
\text { expression and a reduction in lipid } \\
\text { acquisition }\end{array}$ \\
\hline Naowaboot et al. (36) & Mulberry (Morus alba L.) & Moraceae & Methanol & $\begin{array}{l}\text { A stimulatory effect on glucose } \\
\text { uptake via GLUT4 translocation }\end{array}$ \\
\hline Absalan et al. (37) & $\begin{array}{l}\text { Ceylon cinnamon (Cinnamomum } \\
\text { zeylanicum) }\end{array}$ & Lauraceae & Hydro-alcoholic extract & $\begin{array}{l}\text { An increase in glucose uptake in the } \\
\text { 3T3-L1 adipocyte cells }\end{array}$ \\
\hline Lee et al. (39) & $\begin{array}{l}\text { American ginseng (Panax } \\
\text { quinquefolius) }\end{array}$ & Araliaceae & Ginsenosides Rg3 and Re & $\begin{array}{l}\text { An increase in the expression of } \\
\text { GLUT4, IRS-1, and PI3K }\end{array}$ \\
\hline Ku et al. (40) & Green tea (Camellia sinensis) & Theaceae & Epigallocatechin gallate & $\begin{array}{l}\text { The inhibition of glucose uptake } \\
\text { from GLUT } 4 \text { by suppression of the } \\
\text { IGF-I and IGF-II. Stimulation and an } \\
\text { increase in glucose uptake by the } \\
\text { GLUT1 pathway }\end{array}$ \\
\hline Bisht et al. (48) & Devil's cotton (Abroma augusta) & Malvaceae & Petroleum ether & $\alpha$-glucosidase inhibitor \\
\hline Ibraham et al. (50) & $\begin{array}{l}\text { Fenugreek(Trigonella } \\
\text { foenum-graecum) }\end{array}$ & Fabaceae & $\begin{array}{l}\text { Rich extract of sapogenin and } \\
\text { saponin }\end{array}$ & $\begin{array}{l}\text { An inhibitory effect on glucose } \\
\text { uptake in the intestine }\end{array}$ \\
\hline Ademiluyi et al. (51) & Soybean (Glycine max) & Fabaceae & $\begin{array}{l}\text { Extract with phenol and without } \\
\text { phenol }\end{array}$ & $\begin{array}{l}\alpha \text {-glucosidase and } \alpha \text {-amylase } \\
\text { inhibitor }\end{array}$ \\
\hline Shareef et al. (52) & Guduchi (Tinospora cordifolia) & Menispermaceae & $\begin{array}{l}\text { Petroleum ether, chloroform, ethyl } \\
\text { acetate, and methanol }\end{array}$ & $\alpha$-amylase inhibitory activity \\
\hline Kim et al. (54) & Yuzu (Citrus junos Tanaka) & Rutaceae & Ethanol & $\begin{array}{l}\text { An increase in AMPK } \\
\text { phosphorylation and PPAR- } \gamma \\
\text { activation }\end{array}$ \\
\hline Gu et al. (55) & Wax gourd (Benincasa hispida) & Cucurbitaceae & Ethanol & $\begin{array}{l}\text { Inhibition of PPAR- } \gamma \text {, a reduction in } \\
\text { PPAR- } \gamma \text {, mRNA, an improvement in } \\
\text { the lipid profile, and a reduction in } \\
\text { the fasting blood glucose }\end{array}$ \\
\hline Qa'dan et al. (56) & Loquat (Eriobotrya japonica) & Rosaceae & Aqueous extract & The stimulation of insulin secretion \\
\hline Vats et al. (57) & Holy basil (Ocimum sanctum) & Lamiaceae & Ethanol & $\begin{array}{l}\text { A reduction in GK, HK, and PFK } \\
\text { activity }\end{array}$ \\
\hline Liu et al. (58) & $\begin{array}{l}\text { Japanese Dong Quai (Angelica } \\
\text { acutiloba) }\end{array}$ & Apiaceae & Ethanol & A reduction in PEPCK expression \\
\hline Yu et al. (59) & $\begin{array}{l}\text { Common self-heal (Prunella vulgaris } \\
\text { L) }\end{array}$ & Lamiaceae & Methanol & $\begin{array}{l}\text { The inhibition of glycogen } \\
\text { phosphorylase }\end{array}$ \\
\hline Huang et al. (60) & Bitter gourd (Momordica charantia) & Cucurbitaceae & Water extract & An increase in GLP-1 levels \\
\hline Xia et al. (63) & Siam pumpkin (Cucurbita ficifolia) & Cucurbitaceae & Methanol & $\begin{array}{l}\text { Greatly increased D-chiro-inositol } \\
\text { and hypoglycemic activity }\end{array}$ \\
\hline De Paula et al. (64) & Natal grass (Rhynchelytrum repens) & Poaceae & ß-glucan-rich polysaccharides & $\begin{array}{l}\text { The prevention of glucose } \\
\text { absorption }\end{array}$ \\
\hline
\end{tabular}

Abbreviations: AMPK, 5' adenosine monophosphate-activated protein kinase; CAT, catalase; GK, glucokinase; GLP, glucagon-like peptide; GLUT, glucose transporter; GSH, glutathione; GSH-Px, glutathione peroxidase; HbAlc, hemoglobin; HK, hexokinase; IGF, insulin-like growth factor; IRS-1, insulin receptor substrate 1; mRNA, messenger ribonucleic acid; P13K, phosphoinositide-3-kinase; PEPCK, phosphoenolpyruvate carboxykinase; PFK, phosphofructokinase; PPAR- $\gamma$, peroxisome proliferator-activated receptor gamma; SGLT, sodium-dependent glucose co-transporter; SOD, superoxide dismutase. 